\title{
Study on infiltration of Copper-Indium Alloys and Corrosion Resistance of 304 Stainless Steel by Double Glow Technology
}

\author{
Xu jinyong ${ }^{1}$, Wang yiguang ${ }^{1}$, Hao jianmin ${ }^{2}$, Tang Yan ${ }^{1 a}$ \\ ${ }^{1}$ College of mechanical and electrical engineering, Guilin University of Electronic Technology, Guilin Guangxi \\ 541004 China. \\ ${ }^{2}$ School of mechanical engineering, Chang'an University, Xian Shanxi 710064 China.
}

Keywords: Double Glow Technology. 304 Stainless Steel. Corrosion Resistance.

\begin{abstract}
Copper-Indium alloys elements were metallized into 304 Stainless Steel surface by Double Glow Plasma Surface Alloying Technology (Double Glow Technology). Microstructure and Corrosion Resistance of diffusion layer analyzer was analysed by scanning electron microscopy, energy spectrum and electrochemical measuring instrument. The results show that process parameters of the permeability Copper-Indium had an obvious effect for the organization structure and performance of diffusion layer. Electrochemical corrosion tests were carried out in $1 \mathrm{~mol} / \mathrm{L} \mathrm{H} 2 \mathrm{SO} 4$ solution, $1 \mathrm{~mol} / \mathrm{L} \mathrm{NaOH}$ solution, $3.5 \% \mathrm{NaCl}$ solution. The matrix was 3.51 and 2.9 times faster compared with the 304 stainless steel sample of surfacing contained Copper-Indium alloys layer for relativing corrosion rate in $1 \mathrm{~mol} / \mathrm{L} \mathrm{NaOH}$ solution, $3.5 \% \mathrm{NaCl}$ solution. But, the 304 Stainless Steel sample of surfacing contained Copper-Indium alloys layer was 1.21 times faster compared with matrix in $1 \mathrm{~mol} / \mathrm{L} \mathrm{H} 2 \mathrm{SO} 4$ solution.
\end{abstract}

\section{Introduction}

The main features of stainless steel were stainlessness and corrosion resistance. Since the invention of stainless steel, it had a well corrosion resistance and was widely used in food, national defense science and technology, chemical, oil and other industrial sectors. Although stainless steel had excellent corrosion resistance, under certain conditions, corrosion, wear or under certain adverse conditions and then accelerated the corrosion process and material damage and shorten its useful life [1-4]. Therefore, Copper-Indium alloy layer would affect the corrosion performance, it is necessary to discuss. Double Glow Technology is a kind of surfacing modification technology. It has energy saving, low pollution, low cost, simple operation, strong bonding force [5-7]b. Copper-Indium alloys elements were metallized into 304 Stainless Steel surface by Double Glow Technology, 304 Stainless Steel sample after infiltration and matrix divided electrochemical corrosion test in 1mol/L H2SO4 solution, 1mol/L $\mathrm{NaOH}$ solution, $3.5 \% \mathrm{NaCl}$ solution. A corrosion capacity of the 304 Stainless Steel was analysised before and after Copper-Indium was infiltrated.

\footnotetext{
${ }^{a}$ Corresponding author : Tang Yan, 1195957256@qq.com.
} 


\section{Experimental method}

The source material used plate's Copper-Indium alloys. The quality percentage of Copper-Indium alloys for 5:5. No fixed desired size, as long as the source material could be placed in a graphite crucible. Cathode material was 304 Stainless Steel. Dimension was $40 \mathrm{~mm} \times 20 \mathrm{~mm} \times 2 \mathrm{~mm}$. Before the experiment, the surface of the 304 Stainless Steel sample was polished by $2000 \#$ sandpaper.

The initial Copper-Indium alloys process parameters on 304 Stainless Steel were as follows: Argon gas as a medium: Work Pressure:30 35 Pa; Source Voltage: -900V -1000 V; Cathode Voltage: $600 \mathrm{~V} \sim 700 \mathrm{~V}$; Heat Preservation: 4h; Workpiece heat preservation temperature is $900{ }^{\circ} \mathrm{C}$ with furnacing cooling. After infiltration Copper-Indium the 304 Stainless Steel was etched for aqua regia. The sample was preparated by LD-10KW plasma surface alloying. Nitrided layer was observed by SEM. Nitrided layer element distribution was detected by EDS.

The experiment used PS-268A electrochemical measuring instrument. Matrix and 304 Stainless Steel sample of the infiltration of Copper-Indium elements divided electrochemical corrosion test in $1 \mathrm{~mol} / \mathrm{L}$ $\mathrm{H} 2 \mathrm{SO} 4$ solution, $1 \mathrm{~mol} / \mathrm{L} \mathrm{NaOH}$ solution, $3.5 \% \mathrm{NaCl}$ solution. Specific test procedure is as follows:

(1)Samples were cutted out $10 \mathrm{~mm} \times 10 \mathrm{~mm}$ specimen of corrosion by Metallographic cutter.

(2)The beaker was placed in stable work surface as a corrosion solution and into the etching solution.

(3)The auxiliary electrode, working electrode, and a reference electrode were fixed respectively well.

(4)After the samples were etched solution to be $30 \mathrm{~min}$, opening software installed, and the process was activated.

After the relevant parameters were setted up, corrosion polarization curve was worked.

\section{Experimental results and analysis}

\subsection{Sectional morphology and composition of the Copper-Indium alloy layer}

Figure 1 was a cross-section microstructure of infiltration of the 304 Stainless Steel was taken into picture for using SEM. Alloy diffusion layer consisted of layer deposition and diffusion layer, the diffusion layer thickness was $35 \mu \mathrm{m}$. You can see from the chart, no voids between the diffusion layer and the substrate, they had a good combination of properties.

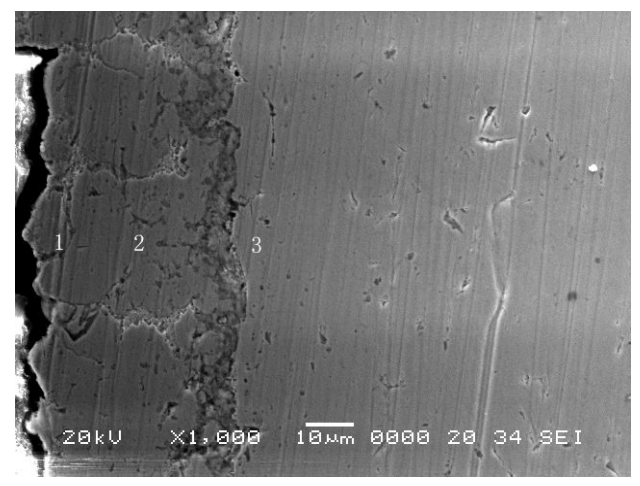

Figure 1. Microstructure of diffusion layer 
As can be understood from Fig.1, the surface of the alloy coating penetration was consisted of deposited layer, diffusion layer of the containing Copper-Indium elements and the substrate. From the figure it was clear that there was a clear over the area between the substrate and the diffusion layer, $\mathrm{C}$ contain of $0.95 \%$ at 3 , much higher than the amount of $\mathrm{C}$ of the substrate. After analysis of observation, this was because some austenite transformed into a ferrite in high temperatures, pearlite thus produced, and the formation of a diffusion layer of dark bands. Cause in the skin layer Copper content was relatively high because the bombardment of high-energy particles of the iron atom was charged sputtered out of the matrix in the surface matrix, such that the surface layer resulted in vacancy defect concentration gradient, Copper atoms which a source bombardment were reached to the surface just to fill this vacancy in the delivery of energy. The lower levels of the Indium element reason was because the radius of Indium atoms is $144 \mathrm{pm}$, and the iron atom atomic radius is $126 \mathrm{pm}$, little difference the radius and the main form of interstitial solid solution exists. Higher Copper content of the reason is because the atomic radius of the Copper atoms is $128 \mathrm{pm}$ and the atomic radius of iron atoms is very close to $126 \mathrm{pm}$ at a high temperature, Copper displaced the iron atom forms exist in matrix. Therefore, the Copper ions diffused deeper than Indium ions.

\subsection{Phase of the Copper-Indium alloy layer}

Figure 2 was based on the experimental diagram optimum process, the X-ray picture of the surface of the 304 Stainless Steel content of coating penetration of Copper-Indium alloy was prepared. Seen from the figure, the main phases of the alloy coating penetration were: $\mathrm{Fe}, \mathrm{Cu}, \mathrm{Cu} 7 \mathrm{In} 3, \mathrm{Cr} 6 \mathrm{Fe} 18 \mathrm{Mn} 5$, $\mathrm{In} 2 \mathrm{O} 3, \mathrm{CuO}, \mathrm{CCuO} 3$ and so on. The surface of the alloy layer contained a large number of Copper ions. one hand, because of the the Copper atoms of some solid solution continuoued accumulation, precipitation of Copper ions of diffusing shaped. On the other hand, since the source was sputtered out a large number of Copper of the reactive ionic groups, part of the Copper ions did not diffuse into the substrate interior, while the surface deposition.

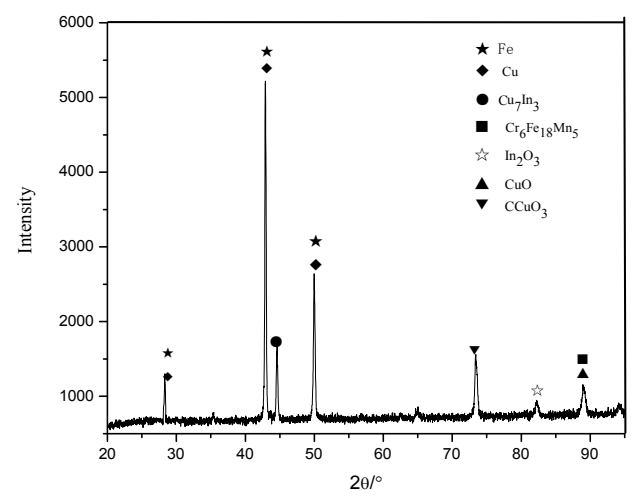

Figure 2 .Nitrided layer surface X-ray diffraction diagrams

\subsection{Results and analysis of corrosion in $3.5 \% \mathrm{NaCl}$ solution}

As shown in Figure 3: The treated 304 Stainless Steel was prepared with baseing on this experiment optimum parameters and the matrix were E-log i curves in $3.5 \% \mathrm{NaCl}$ solution. 


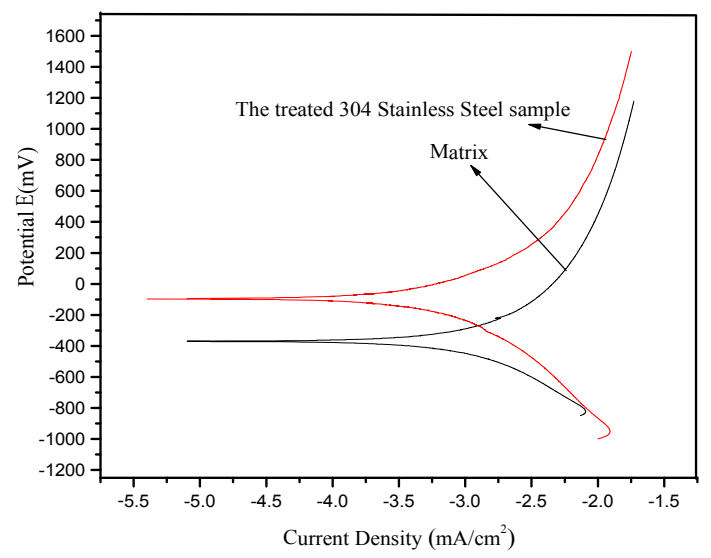

Figure 3. E-log i curve of the treated 304 Stainless Steel and the matrix in $3.5 \% \mathrm{NaCl}$ solution

As can be seen from Figure 3, 304 Stainless Steel sample of the surface contained of Copper-Indium alloy coating penetration and substrates had appeared with increasing of polarization potential of corrosion, corrosion current density were both followed reduced in cathodic polarization phase. When the potential was rose to $-397 \mathrm{mV}$, matrix began to take the lead into the anodic polarization stage compared to the treated 304 Stainless Steel sample. When the potential was risied to $1100 \mathrm{mV}$, corrosion current density was gradually stabilize. At this time, Matrix began to the passive region, and when the potential was rose to $-100 \mathrm{mV}$, the treated 304 Stainless Steel began to enter the anodic polarization stage. When the potential was raised to $1450 \mathrm{mV}$, the treated 304 Stainless Steel began to enter the passive range. Corrosion potential of the treated 304 Stainless Steel sample than the corrosion potential of the matrix to improve $297 \mathrm{mV}$, from point of view of the thermodynamics, the treated 304 Stainless Steel sample was more corrosion resistance than the matrix in $3.5 \% \mathrm{NaCl}$ solution.

\subsection{Results and analysis of corrosion in $1 \mathrm{~mol} / \mathrm{L} \mathrm{H}_{2} \mathrm{SO}_{4}$ solution}

As shown in Figure 4: The treated 304 Stainless Steel was prepared with baseing on this experiment optimum parameters and the matrix were E-log i curves in $1 \mathrm{~mol} / \mathrm{L} \mathrm{H} 2 \mathrm{SO} 4$ solution.

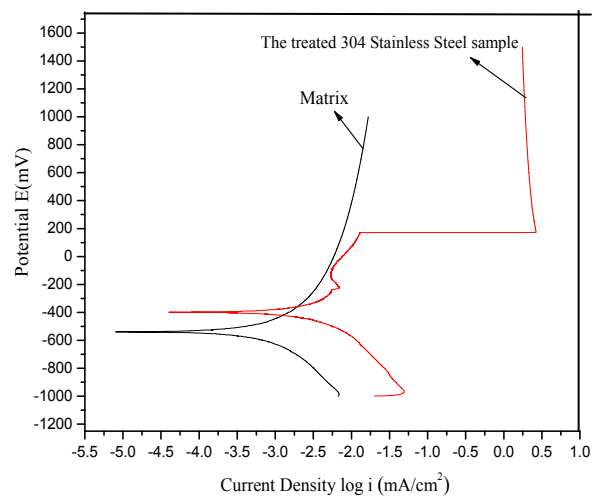

Figure 4. E-log i curve of the treated 304 Stainless Steel and the matrix in $1 \mathrm{~mol} / \mathrm{L} \mathrm{H}_{2} \mathrm{SO}_{4}$ solution 
As can be seen from Figure 4, the treated 304 Stainless Steel sample and the matrix had appeared with increasing of polarization potential of corrosion, corrosion current density were both followed reduced in cathodic polarization phase. When the potential was rose to $-539 \mathrm{mV}$, the treated 304 Stainless Steel sample began to take the lead into the anodic polarization stage compared to matrix. At this time, with the further increased of the potential, the corrosion current density of the matrix was increased. When the potential was raised to $1000 \mathrm{mV}$, the treated 304 Stainless Steel sample began to take the lead into the passive region. Passivation film was gradually thickened, the corrosion current density of the treated 304 Stainless Steel sample was $0.00827 \mathrm{~mA} \cdot \mathrm{cm}^{-2}$. The same to the matrix, the potential was raised to $-399 \mathrm{mV}$, the matrix began to enter the anodic polarization stage, and the corrosion current density was increased with increasing voltage. From point of view of the thermodynamics, corrosion tendency of the matrix even better than the treated 304 Stainless Steel sample in $1 \mathrm{~mol} / \mathrm{L} \mathrm{H}_{2} \mathrm{SO}_{4}$ solution. Howerer, after a very short range potential, when the potential was raised to $-173 \mathrm{mV}$, the matrix began to enter the passive region, which also showed the matrix was formed on stability of the passive film no better than the treated 304 Stainless Steel sample. After the matrix was entered the passive region, the corrosion current density was $0.00679 \mathrm{~mA} \cdot \mathrm{cm}^{-2}$. A

\subsection{Results and analysis of corrosion in $1 \mathrm{~mol} / \mathrm{L} \mathrm{NaOH}$ solution}

As shown in Figure 5: The treated 304 Stainless Steel sample was prepared with baseing on this experiment optimum parameters and the matrix were E-log i curves in $1 \mathrm{~mol} / \mathrm{L} \mathrm{H} 2 \mathrm{SO} 4$ solution.

As can be seen from Figure 5, the treated 304 Stainless Steel sample and the matrix had appeared with increasing of polarization potential of corrosion, corrosion current density were both followed reduced in cathodic polarization phase. When the potential was raised to $-229 \mathrm{mV}$, the matrix began to take the lead into the anodic polarization stage compared to the treated 304 Stainless Steel sample. Then the potential was continued to rise, the matrix was showed its instability, it showed that the production process of the passivation film was unstable, when the potential was rose to $209 \mathrm{mV}$, the matrix began to enter the passive region; and the treated 304 Stainless Steel sample began to enter the anodic polarization stage when the potential was rose to $-162 \mathrm{mV}$.

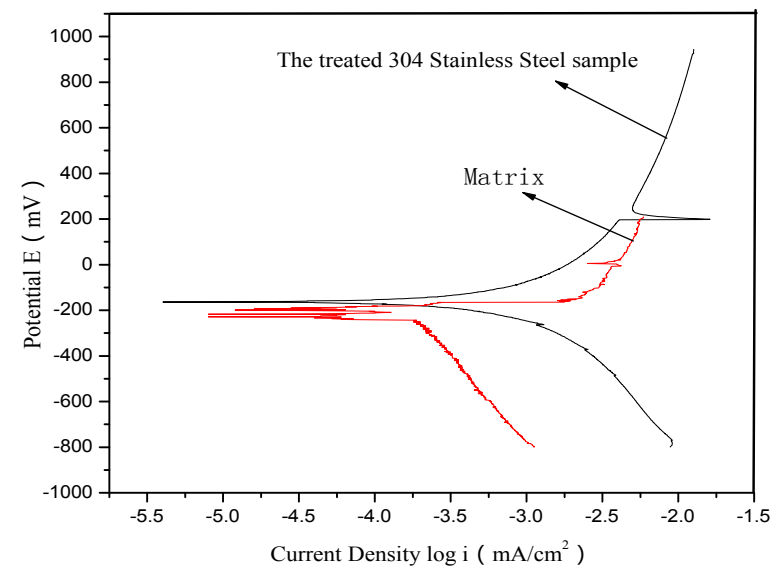

Figure 5. E-log i curve of the treated 304 Stainless Steel and the matrix in $1 \mathrm{~mol} / \mathrm{L} \mathrm{NaOH}$ solution

From point of view of the thermodynamics, the treated 304 Stainless Steel sample was more corrosion resistance than the matrix in $1 \mathrm{~mol} / \mathrm{L} \mathrm{NaOH}$ solution. When the potentia was continued to rise, the corrosion current density was increased along. When the potential was rose to $944 \mathrm{mV}$, the treated 304 
Stainless Steel sample began to enter the passive region. Corrosion current density of the treated 304 Stainless Steel sample and the matix were $0.0039 \mathrm{~mA} \cdot \mathrm{cm}^{-2}$ and $0.0137 \mathrm{~mA} \cdot \mathrm{cm}^{-2}$. From point of view of the kinetic, the treated 304 Stainless Steel sample was more corrosion resistance than the matrix in 1 $\mathrm{mol} / \mathrm{L} \mathrm{NaOH}$ solution.

\section{Conclusions}

(1) The diffusion layer thickness the surface of the 304 Stainless Steel of penetration Copper-Indium alloy had about $35 \mu \mathrm{m}$, diffusion layer uniform density, diffusion layer of combining with well.

(2) The matrix was 3.51 and 2.9 times faster compared with the treated 304 Stainless Steel sample in $1 \mathrm{~mol} / \mathrm{L} \mathrm{NaOH}$ solution, 3.5\% NaCl solution. But, the 304 Stainless Steel sample of surfacing contained Copper-Indium alloys layer was 1.21 times faster compared with matrix in 1mol/L H2SO4 solution.

\section{Acknowledgement}

It is a project supported by the National Natural Science Foundation of China (51361008).

\section{References}

[1] HE Yaohua, LIU Jun, HE Zhiyong, WANG Zhenxia. Study on Corrosion and Antibacterial Properties of Ag-Cu Modification Layer on 304 Stainless Steel Surface [J]. Hot Working Technology, 2010, 39(24): 179.

[2] Wang xiaoli. The effects of heat treatment on properties of high-Cu martensite stainless steel [D]. Liaoning: Liaoning Project Technology University, 2006: 3.

[3] T.Bell, X.Y.Li, Y.Sun. Towars Improving the Corrosion Characteristics of Plasima Nitrided Austenitic Stainless Steels[J]. CHINA SURFACE ENGINEERIGN, 1998, (4): 40-48.

[4] Du Chunchen. Application of Austenitic Stainless Steel in Industry[J]. Process Equipment \& Piping, 2003, 40(2): 54-57.

[5] Xu zhong. Double Glow Plasma Surface Alloying Technology[J]. Transactions of Materials and Heat Treatment, 1982(1): 71.

[6] Gao yuan, Xu jinyong, Gao qing, An jinping, Xu zhong. Research on Characteristic of Double Glow Discharge Plasma Surface Alloying Process[J]. Engineering Sciences, 2008, 02: 26 30.

[7] Gao yuan, Xu Jinyong, Gao qing, Cheng jun, Xu zhong. Analysis on Characteristics of Double Glow Discharge Plasma Surface Alloying Process[J]. Hot Working Technology, 2006, 03: 56 59. 